\title{
Subsurface Investigation of Basement Structures Using Electrical Resistivity Methods at Zainawa Village Kano, Nigeria
}

\author{
Ahmed A Lawal ${ }^{1}$ and Adamu Abubakar ${ }^{2}$ \\ ${ }^{1}$ Department of Physics, Ahmadu Bello University, Zaria, Kaduna State, Nigeria \\ ${ }^{2}$ Department of Applied Geophysics, Federal University Birnin Kebbi, Kebbi State, Nigeria \\ Corresponding E-mail: aminuahmad777@gmail.com
}

Received 25-02-2021

Accepted for publication 08-04-2021

Published 14-04-2021

\begin{abstract}
Electrical Resistivity Methods involving Schlumberger Vertical Electrical Sounding (VES) and Wenner Electrical Profiling (EP) were carried out to map the Geological features of the earth subsurface in Zainawa Area of Kano State, Nigeria. Five profiles were established; consist of six (6) VES points at each profile. GEOPULSE resistivity meter (SAS 300) was used for the data acquisition. The field data obtained have been analyzed using computer software (IPI2win) which gives an automatic interpretation of the apparent resistivity. A maximum of three geoelectric subsurface layers were delineated from the VES master curves. The geoelectric section beneath the study area was composed of top soil (clayey-sandy and sandy-lateritic), weathered layer, partly weathered (fractured basement) and fresh basement. The resistivity value for the topsoil layer varies from $20 \Omega \mathrm{m}$ to $600 \Omega \mathrm{m}$ with thickness ranging from 0.5 to 7.2 $\mathrm{m}$. The weathered basement has resistivity values ranging from $15 \Omega \mathrm{m}$ to $593 \Omega \mathrm{m}$ and thickness of between 2.75 to $33.04 \mathrm{~m}$. The fractured basement has resistivity values ranging from 201 $\Omega \mathrm{m}$ to $835 \Omega \mathrm{m}$ and thickness of between 11 to $20.4 \mathrm{~m}$. The fresh basement (bedrock) has resistivity values ranging from $1161 \Omega \mathrm{m}$ to $3115 \Omega \mathrm{m}$ with infinite depth. The depth to basement map was produced to give a good picture of the basement topography within the study area. The depth to basement ranges from $11 \mathrm{~m}$ around VES 01 to $85 \mathrm{~m}$ around VES $25 \mathrm{~m}$. The map also reveals linear structures (VES 05, 21, 22 and VES 23) which trends in the NE-SW direction. These structures suggest a basement depression at these points. However, the depth from the topsoil to the bedrock surface varies between 2.5 to $37.75 \mathrm{~m}$.
\end{abstract}

Keywords: Vertical Electrical Sounding (VES); Weathered Basement; Geopulse Metre; Zainawa Village 


\section{INTRODUCTION}

$\mathrm{T}^{\mathrm{s}}$ he purpose of electrical survey is to determine the subsurface resistivity distribution by making measurements on the ground surface. From these measurements, the true resistivity of the subsurface can be estimated. The ground resistivity is related to various geological parameters such as mineral and fluid contents, porosity and degree of water saturation in the rock [1]. Electrical resistivity surveys have been used for many decades in hydrogeological, mining and geotechnical investigations. More recently, it has been used for environmental surveys. The resistivity measurements are normally made by injecting current into the ground through two current electrodes $\left(C_{1}\right.$ and $C_{2}$ ), and measuring the resulting voltage difference at two potential electrodes $\left(P_{1}\right.$ and $\left.P_{2}\right)$. From the current (I) and voltage $(\mathrm{V})$ values, an apparent resistivity value is calculated. Resistivity meters normally give a resistance value, $R=V / I$, so in practice the apparent resistivity value is calculated by $\left(\rho_{a}=K D V / I\right)$. The calculated resistivity value is not the true resistivity of the subsurface, but an 'apparent' value which is the resistivity of a homogeneous ground which will give the same electrode arrangement. To determine the subsurface resistivity, an inversion of the measured apparent resistivity values using a computer programme must be carried out. The resistivity method has its origin in the 1920's due to the work of the Schlumberger brothers. For approximately the next 60 years, quantitative interpretation, conventional sounding surveys [1] were normally used. In this method, the center point of the electrode array remains fixed, but the spacing between the electrodes is increased symmetrically to obtain more information about the deeper sections of the subsurface. In many engineering and environmental studies, the subsurface geology is very complex where the resistivity can change rapidly over short distances. The resistivity sounding method cannot be sufficiently accurate for such situations [1]. Despite its obvious limitations, there are two main reasons why 1-D resistivity sounding surveys are common. The first reason is the lack of proper field equipment to carry out the more data intensive 2-D and 3-D surveys. The second reason is the lack of practical computer interpretation tools to handle the more complex 2-D and 3-D electrical are now practical commercial techniques with the relatively recent development of multi-electrode resistivity surveying instruments [2] and fast computer inversion software [3].

\section{A. Location and Accessibility of the Study Area}

Zainawa village via Jogana is situated within the Northern Nigerian Basement Complex, in Gezawa Local Government Area of Kano State $18 \mathrm{~km}$ South East of Jigawa State. The survey area is bounded by latitude $12^{\circ} 46^{\prime}-12^{\circ} 89^{\prime}$ North and longitude $08^{\circ} 26^{\prime}-08^{\circ} 52^{\prime}$ East with an average elevation of $600 \mathrm{~m}$ above sea level. The accessibility to the Zainawa village is only by the Kano-Jigawa road which is a prominent federal road. A number of all-season motorable roads, some of which are old tarred roads also exist within the village (See Fig. 1).

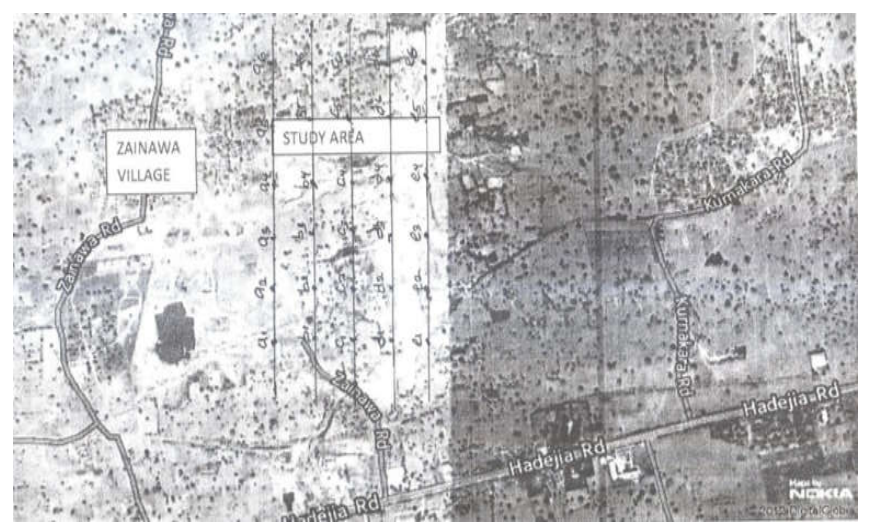

Fig. 1 Satellite Imagery of the Study Area (Adopted from Google earth map)

\section{B. Geology of The Study Area}

Regionally, the rocks in the study area are mostly Precambrian in age. These have been subjected to several deformities, the latest being the Pan - African orogeny [4]. This thermo tectonic event has virtually obliterated the imprints but left it is own structural landmarks, which includes folding, fracturing, shearing, granitic emplacement and granitization. The rock of the Basement Complex occupies more than $50 \%$ of the total land surface of Nigeria, and accommodates the metasediments which are made up gneiss. Exposure is scanty and highly weathered and decomposed. The rock types are biotite, gneiss, granite gneisses and in parts with subordinate migmatites. The contact between the gneiss and metasediments are gradation [4] (Fig. 2).

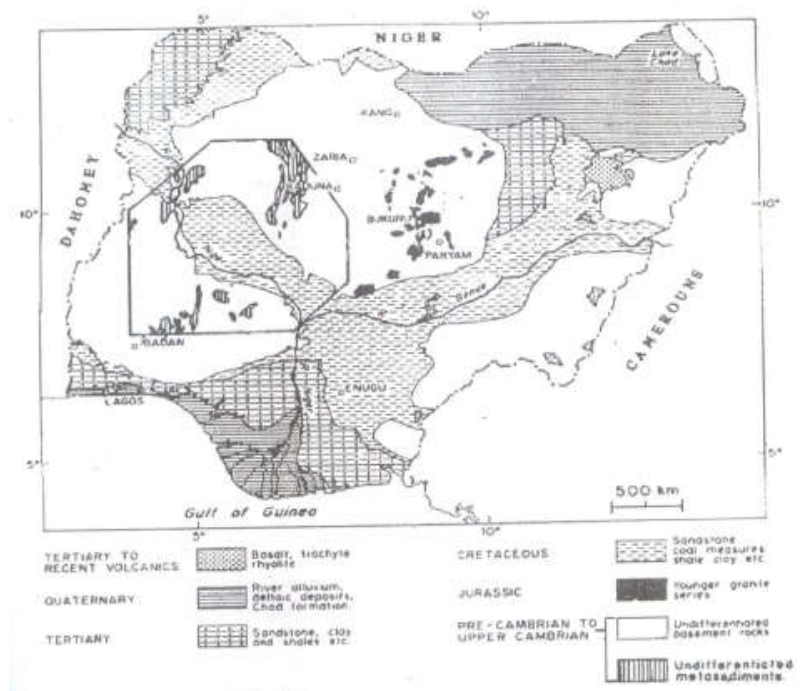

Fig. 2 A Generalized Geological Map of Nigeria Showing the Study Area [13] 


\section{MATERIALS AND METHOD}

\section{A. Instrumentation and Field Layout}

This study used GEOPULSE Ohm Terameter SAS 300 model for hydrogeological and other geological features involving Schlumberger Vertical Electrical Sounding (VES) and the Wenner Horizontal Electrical Profiling covering a total area of $300 \mathrm{Km}^{2}$. The Schlumberger electrodes configuration was used in carrying out the vertical electrical soundings at a separation of $70 \mathrm{~m}$ covering an area of $300 \mathrm{Km}^{2}$. A profile with a total of 6 VES stations was established on each of the profile 1, 2, 3, 4 \& 5. Data collected from the Vertical Electrical Soundings were processed using IP12Win (a software for interpreting Vertical Electrical Sounding) and the results was used to determine the thickness of the overburden and weathered basement within the area of study. The horizontal electrical profiling was carried out along the pre-selected profiles, data collected from the horizontal electrical profiling were processed using the surfer 12 (a software for interpreting Horizontal Electrical Profiling) and the result was used to locate the anomalous areas of interest.

\section{B. Schlumberger Electrodes Configuration for Vertical Electrical Sounding}

In this array, the current electrodes are spaced much further apart than the potential electrodes (Fig. 3). The electric field is measured approximately. The apparent resistivity is given as

$$
\rho_{a}=\pi\left(\frac{l^{2}}{2 b}-\frac{b}{2}\right) \frac{\Delta V}{I}
$$

Where $l$ is the distance of the current electrode from the Sounding, point and $\mathrm{b}$ is the potential electrode distance from the sounding point. sounding, the potential electrodes are fixed while the current electrode separation is increased symmetrically about the Centre of the spread, Schlumberger soundings are carried out under the constraint potential electrode spacing $(\mathrm{MN})$ is small compared to the current electrode spacing $(A B)$ i.e., $M N<A B / 2$.

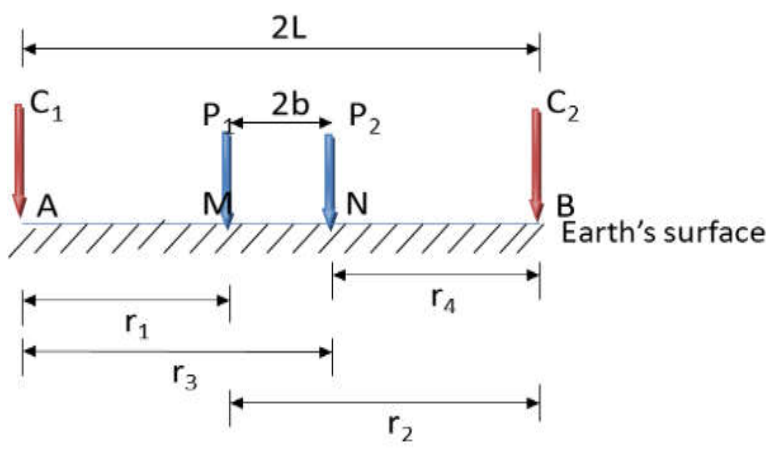

Fig. 3 The Schlumberger array (A and B are current electrodes while $\mathrm{M}$ and $\mathrm{N}$ are potential electrodes)

\section{The Wenner Electrode Configuration for Horizontal Profiling}

The Wenner electrode Geometry is illustrated in Fig. 4.

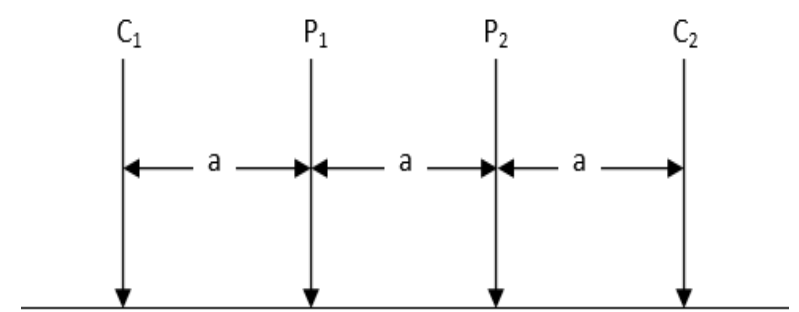

Fig. 4 The Wenner Electrodes Configuration

Spacing between all electrodes is equal and conventionally denoted by letter ' $a$ ' in conducting the horizontal electrical profiling, with this configuration all electrodes are moved along a straight line or between the selected profiles after every reading such that the spacing between electrodes remains equal and takes on certain preselected values [5]. The general equation for the apparent resistivity in this configuration is given by

$$
\rho_{a}=2 \pi a \frac{D V}{I}
$$

In this case, the survey was carried out along the profiles on the same VES profiles. The electrodes spacing remained constant and moved along a profile of $200 \mathrm{~m}$. This method is widely employed to locate faults or shear zones and detect localized bodies of anomalous conductivity. It is also used in geotechnical surveys to determine variations in bedrock depth and can also indicate the presence of potentially unstable ground conditions [6].

\section{RESULTS AND DISCUSSION}

\section{A. Interpretation of Resistivity Data}

An inclusive quantitative interpretation of apparent resistivity data is often difficult because of the wide variations in resistivity possessed by geological materials and the difficulty in developing theoretical expressions for apparent resistivity's of all but the simplest geometries [7]. There are so many methods of interpreting apparent data, these are the empirical methods which included Moore Cumulative Resistivity Method [8] and the [9] layer Method. Analysis Methods; this involved the curve matching, the computerbased etc.

Though computer-based approach is suggested by [10], recently, due to the advancement in modern technology, different computer program have been designed to ease the ambiguity in the interpretation of apparent resistivity data. However, because of the problem of equivalence and suppression and because of the many factors that affect curve details, a thorough knowledge of resistivity principles and as much experience as, possible must go hand-in-hand with computer-derived solutions for field measurements [7]. In this research IP12Win is used in Vertical electrical sounding interpretation while Surfer V.12 is used for the electrical profiling interpretation. 


\section{B. Interpretation of Resistivity Data}

The value of the apparent resistivity at each sounding point was calculated from the resistance values obtained in the field and presented as sounding curves using IP12win. The results of the interpreted VES curves along the five profiles were used prepare 2-D geologic sections along the six profiles (Fig. 5, 6, 7,8 and 9). The numbers of layers vary between two and four layers.

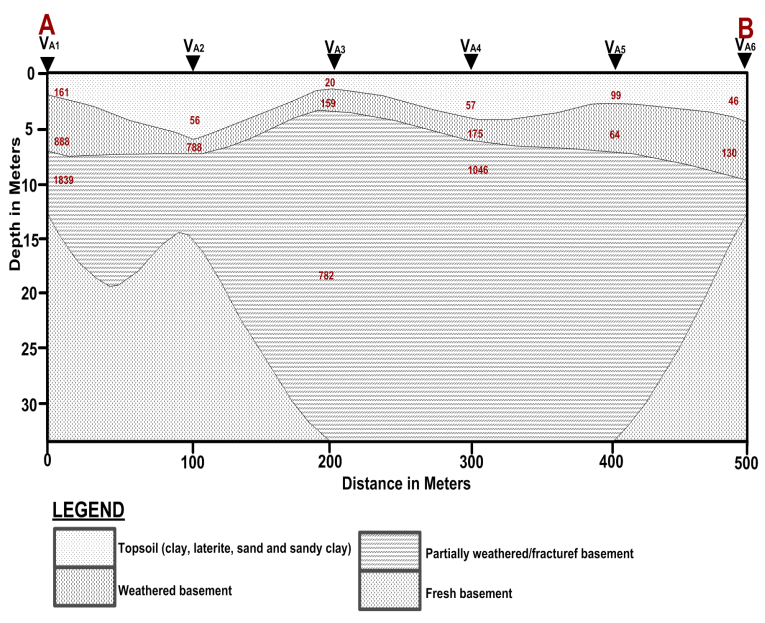

Fig. 5 Geoelectric Section Along Profile A-B

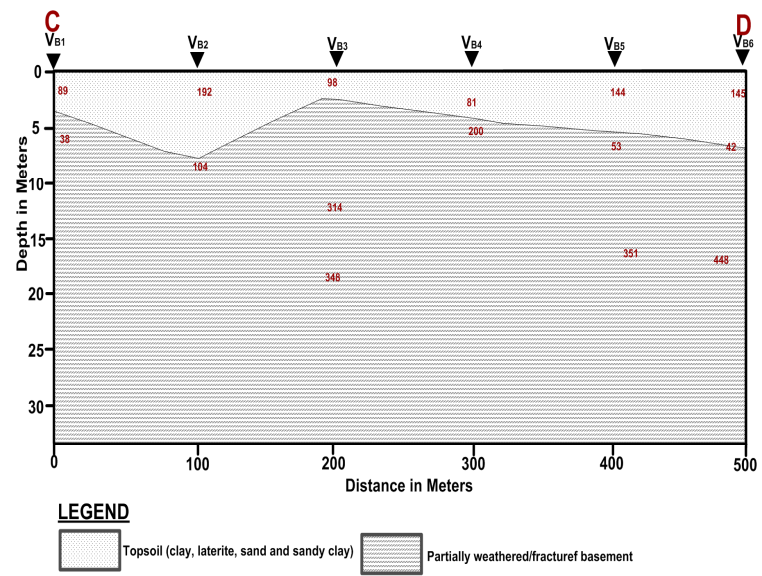

Fig. 6 Geoelectric Section Along Profile C-D

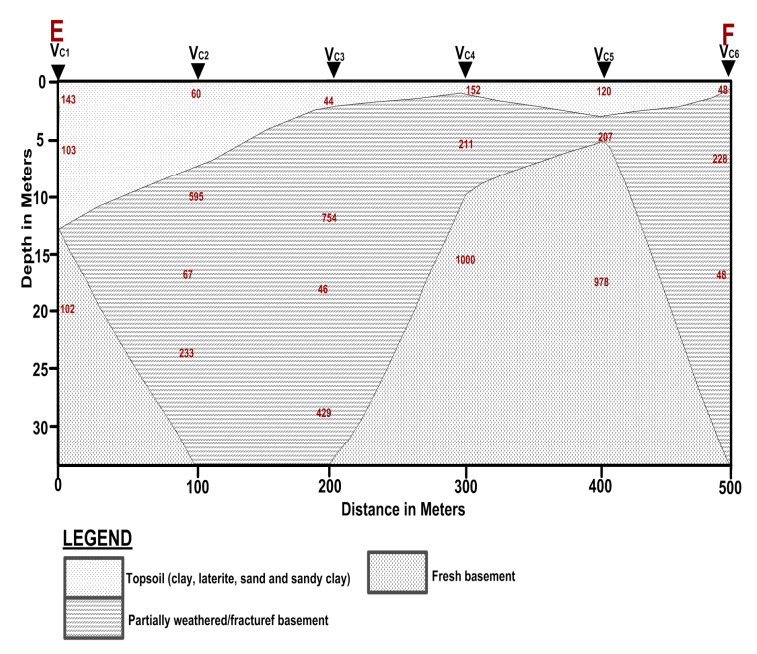

Fig. 7 Geoelectric Section Along Profile E-F

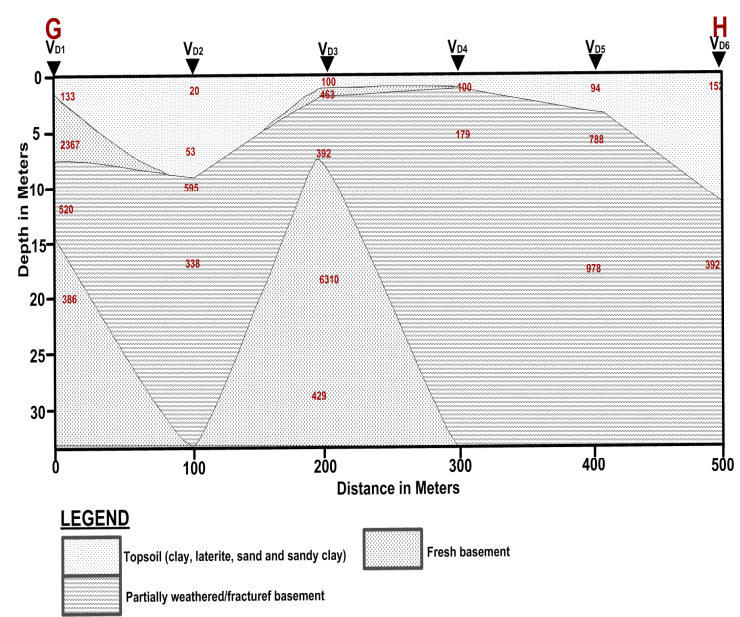

Fig. 8 Geoelectric Section Along Profile G-H 


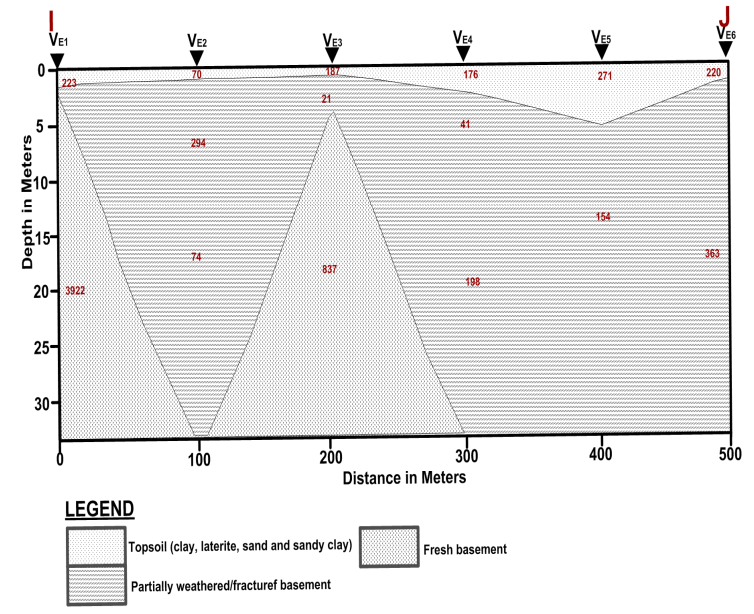

Fig. 9 Geoelectric Section Along Profile I-J

The geoelectric sections delineate a maximum of three geoelectric subsurface layers comprising the top soil layer, weathered/fractured basement and fresh basement. The top soil layer has resistivity values ranging from $20 \Omega \mathrm{m}-192$ $\Omega \mathrm{m}$. These indicate that the resistivity of the top layer varies from place to place across the entire profile. The main factor that controls the resistivity of this layer is the moisture content within the formation. The second layer resistivity varies between $38 \Omega \mathrm{m}-520 \Omega \mathrm{m}$, this indicates that it is the weathered basement (as in Profile E-F) the resistivity of this layer at VES C3 is low compared to VES C4 and C5. This layer with low resistivity is most likely the most conductive layer under the profile. The third layer is the Partially weathered to fractured basement, this layer likely undergone the weathering process due to the presence of fracture within the basement its resistivity value ranges from $170 \Omega m-$ $888 \Omega \mathrm{m}$ at a depth of $5.8 \mathrm{~m}-10 \mathrm{~m}$ with an average of $3.5 \mathrm{~m}$.

It's been reported in [11] that typical resistivity ranges for lateritic soils is within the range of $200 \Omega \mathrm{m}-500 \Omega \mathrm{m}$. It's on this premise that the overburden $(170 \Omega m-888 \Omega m)$ was identified as lateritic soil. However, the resistivities greater than $100 \Omega m$ suggests the presence of weathered bedrock [12].

\section{The Horizontal Electrical Profiling Interpretation}

Electrical resistivity Profiling (EP) survey was conducted in the survey area along the five profile lines. Fig. 10 show the map of resistivity of overburden. The map was produced by contouring the resistivity values of the overburden at all the 30 VES points within the study area. A contour interval of $20 \Omega m$ was used for the map. The resistivity values of the top soil vary between 55 to $367 \Omega m$ and the N-W area has lower resistivity values found to range 19 to $30 \Omega \mathrm{m}$ respectively.
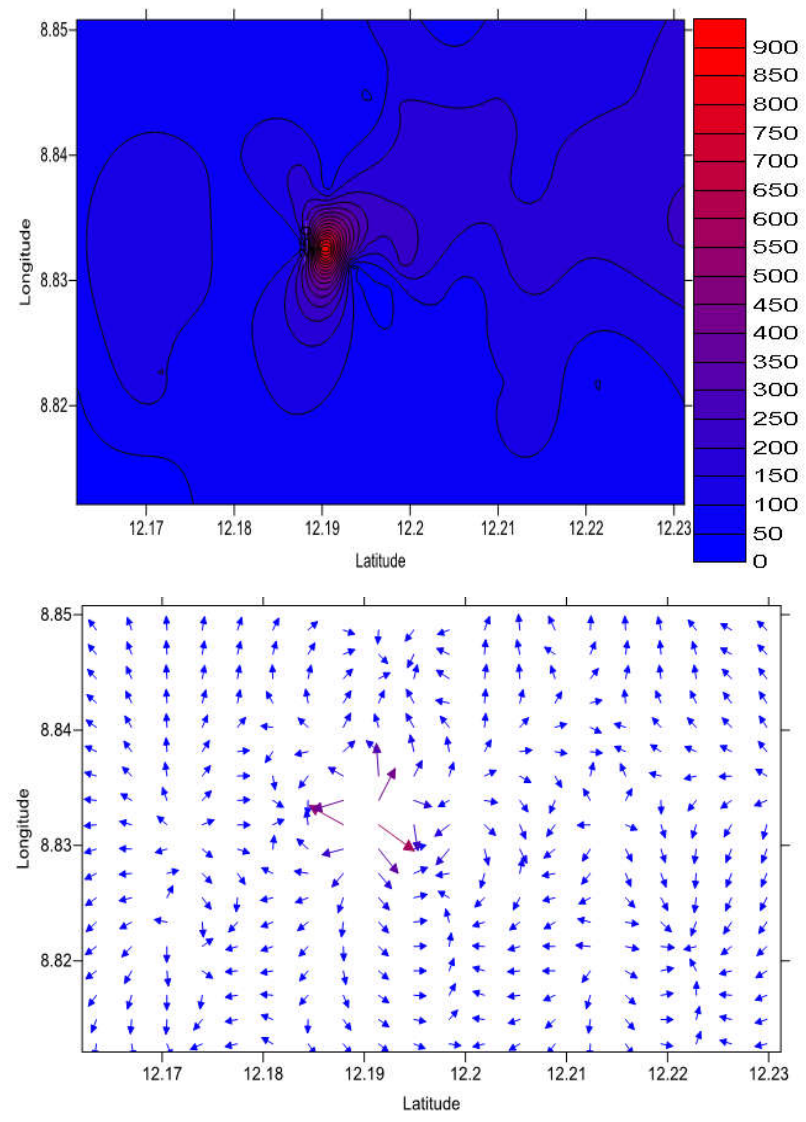

Fig. 10 Map of Resistivity of Overburden (Contour Interval 20 ohm-meters)

\section{Depth to Basement and Thickness of Overburden}

The depth to basement contour map for the study area is shown in Fig. 11b. The map was produced from the interpreted depth to fresh basement at each VES station. This map gave a good picture of the basement topography in the study area. The map shows that the basement topography is rugged or undulating being deeper at some points and shallower at other points. The depth to basement ranges from $11 \mathrm{~m}$ around VES01 to $85 \mathrm{~m}$ around VES23. The map also reveals linear structure (VES 05, 21, 22 and VES 23) which trends in the NE - SW direction. This structure suggests a basement depression at these points. The thickness map was produced by contouring all the thicknesses of the first layer at each VES point at an interval of $0.5 \mathrm{~m}$. The map is shown in Fig. 11a, and it indicates the variation of the topsoil thickness from one place to another. The thickness varies from $0.2 \mathrm{~m}$ to $5.2 \mathrm{~m}$, 
with an average of $2.1 \mathrm{~m}$. The lowest thickness is at VES 27 where the depth to basement is as low as $10 \mathrm{~m}$.
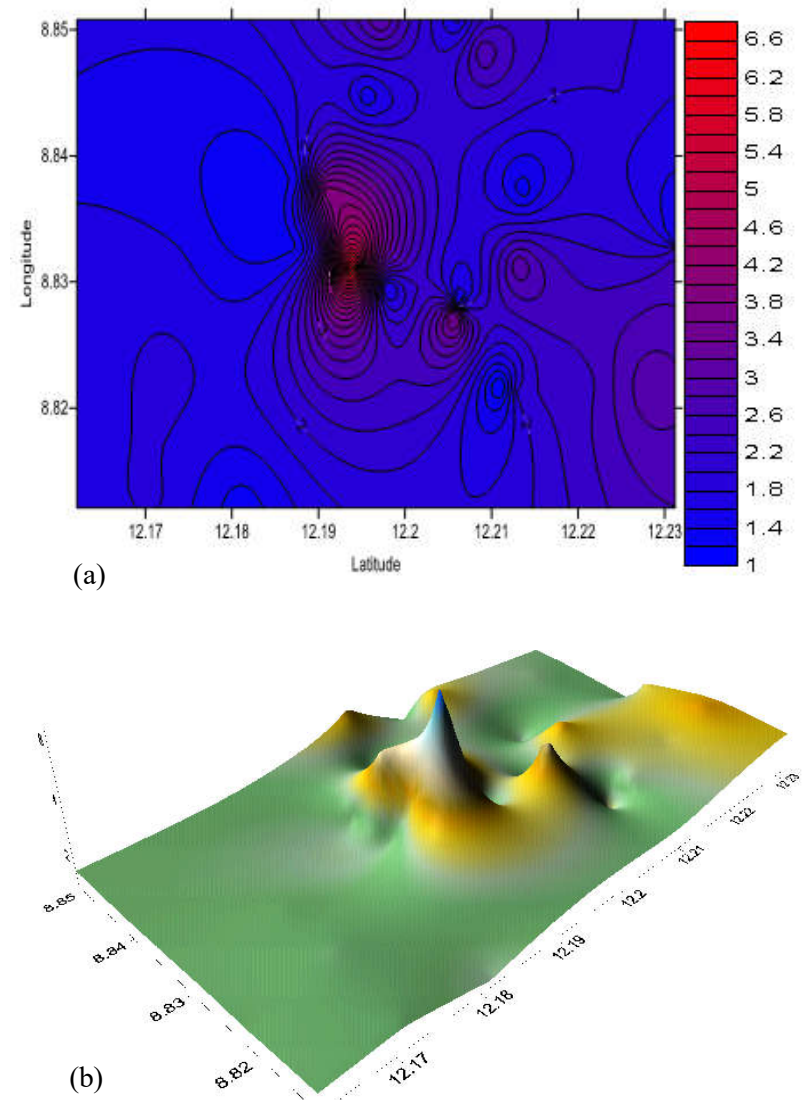

Fig. 11(a) Overburden Thickness Map and (b) Depth to Basement Map

\section{CONCLUSION}

The geoelectric sections were carefully examined to see the regions where extensive weathering occurs along fractures. These together with information obtained from such maps as; depth to basement, aquifer thickness led to the conclusion that: VES points A2, A3, A4, B1, B5, C4, D3, D4, E1, E2, E3 and E6 have the greatest groundwater potentials in the area and are suitable for dug well, and borehole development. VES points A5, D4, D5 and E1 fall on the linear region of the basement depression shown on the depth to basement map. Also thickness of the weathered/fractured basement beneath the region was found to be considerably large about $18 \mathrm{~m}$. The aquifer thickness map of the study area suggests that the thickness of the weathered/fractured basement layer vary from 1-21 m. Areas with low resistivity values at great depth imply structural disturbance which may have cause by fracturing of the bedrock. The basement rocks with resistivity values greater than $2000 \Omega m$ are less weathered and contain little or no quantity of ionize water.

\section{References}

[1] O. Koefoed, "Geosounding Principles1: Resistivity Sounding Measurements". Elsevier Science Publication, Amsterdam, pp. 49-55. 1979.

[2] D. H. Griffiths, J. Turnbull, and A. I. Olayinka, "Two-Dimensional Resistivity Mapping with a Computer-Controlled Array". First break, vol. 8, pp. 121-129, 1990.

[3] M. H. Loke, "The Inversion of Two-dimensional Resistivity Data. Unpublished $\mathrm{PhD}$ thesis, University of Birmingham, United Kingdom, pp. 106-124, 1994.

[4] P. L. McCurry, "The Geology of Degree Sheet 21 (Zaria)". Unpublished MSc Thesis, Department of Geology, Ahmadu Bello University, Zaria, pp.103107, 1975.

[5] A. A. Bowen, "IPI2win User Guide. Moscow State University, Geological Faculty, Department of Geophysics. Geoscan-MLTD, pp. 96-104, 1986.

[6] P. Kearey, B. Michael and H. Ian, "An Introduction to Geophysical Exploration", $3^{\text {rd }}$ edition, Blackwell Publishing, Malden M.A, United State of America, pp. 202-216, 2002.

[7] P. K. Bhattacharya and H. P. Patra, "Direct Current Geoelectric Sounding”. Elsevier, Amsterdam, vol. 2, no. 1, pp. 32-44, 1968.

[8] H. M. Mooney and E. Orellana, "Master Tables and Curves for electrical sounding over layered Structure Interciencia, vol. 1, no. 2, pp. 34-41, 1966.

[9] H. E. Barnes, "Soil Mechanics in Road Construction for Electrical Resistivity Sounding". Butter and Tanner Publishing Company, Great Britain, pp. 2325, 1952.

[10] A. Zohdy, "The Auxiliary Point Method of Electrical Sounding Interpretation, and its Relationship to the Dar Zarrouk Parameters". Geophysics, vol. 30, no. 4, pp. 644-660, 1965. doi: 10:1190/1.1439636.

[11]H. O. Aboh, "Detailed Regional Geophysical Investigation of the Subsurface Structures in Kaduna Area. Nigeria. Unpublished $\mathrm{PhD}$ Thesis, A.B.U. Zaria, pp. 54-62, 2001.

[12]DMTC, Delta Mine Center, Alaska: Resistivities of Common Rocks/Materials and Selected Ore Minerals, pp. 40-49, 2006.

[13]C. A. Kogbe, Geology of Nigeria. Rock View (Nigeria) Limited, plot 1234, Zaramaganda, Jos, Nigeria. pp. 348-350, 1989. 